\title{
Guanosine Triphosphatase Activity of the Human Coronavirus Helicase
}

\author{
ANJA SEYBERT AND JOHN ZIEBUHR \\ Institute of Virology, University of Würzburg, 97078 Würzburg, Germany
}

\section{INTRODUCTION}

RNA helicases are a diverse class of enzymes that use the energy of nucleoside triphosphate (NTP) hydrolysis to unwind duplex RNA structures. They are involved in virtually every aspect of RNA metabolism, including transcription, RNA splicing, translation, RNA export, ribosome biogenesis, mitochondrial gene expression and regulation of mRNA stability (Schmid and Linder 1992, Lohman and Bjornson 1996, Kadaré and Haenni 1997). On the basis of conserved sequence motifs, helicases have been divided into 3 large superfamilies (SF), SF1 to SF3, and two smaller families (Gorbalenya et al. 1989, Gorbalenya and Koonin 1993b), which contain both RNA and DNA helicases.

Apart from the RNA-dependent RNA polymerases (RdRp), helicases are the most conserved subunits of the replication machinery of $(+)$ RNA viruses (Gorbalenya et al. 1988, Gorbalenya and Koonin 1993a, Koonin and Dolja, 1993). Thus, based on sequence analyses, putative helicase domains have been identified in most $(+)$ RNA virus genomes and there is a large body of genetic and reverse-genetic information to suggest a key function of helicases in the life-cycle of (+)RNA viruses (Kadare and Haenni 1997). Remarkably, (-)RNA viruses and retroviruses do not encode helicases (Gorbalenya et al. 1988). While a number of (+)RNA virus helicases of SF2 have been characterized in considerable detail, there is nearly no information on the biochemical properties of RNA virus SF1 helicases. The latter superfamily includes putative helicases from more than $15(+)$ RNA virus 
families but, to date, no convincing evidence for duplex-unwinding activity has been obtained for most of these proteins.

The human coronavirus $229 \mathrm{E}(\mathrm{HCoV})$ replicase gene encodes two large polyproteins that are extensively processed by virus-encoded proteinases (Ziebuhr et al. 2000). One of the mature processing products, $\mathrm{p} 66^{\mathrm{HEL}}$, has previously been predicted to contain an SF1 helicase domain (Gorbalenya et al. 1988). Biochemical data to support these predictions have recently been reported (Seybert et al. 2000). Specifically, clear evidence was presented to show nucleic acid duplex-unwinding activity associated with this viral protein. Interestingly, the functional analysis of $\mathrm{p} 66^{\mathrm{HEL}}$ revealed a $5^{\prime}$-to-3' polarity of the unwinding reaction, whereas SF2 RNA virus helicases have been shown to operate in $3^{\prime}$-to-5' direction.

\section{MATERIALS AND METHODS}

\subsection{Protein Expression and Purification Using Baculovirus Recombinants}

The construction of baculovirus recombinants expressing recombinant forms of $\mathrm{p}^{\mathrm{HEL}}$ has been described previously (Seybert et al. 2000). Briefly, the coding sequence of the HCoV pplab amino acids 4998 to 5592 was inserted into pBlueBacHis2B DNA (Invitrogen; Groningen, Netherlands). The resultant plasmid, pBlueBacHis2B-Hel, essentially encodes the complete $\mathrm{HCoV}$ helicase domain fused to an amino-terminal histidine tag.

A recombination-PCR method was used to introduce a point mutation into the helicase-coding sequence of pBlueBacHis2B-Hel. In the resultant plasmid, pBlueBacHis2B-Hel-KA, the codon for the HCoV pplab amino acid Lys-5284, AAA, was substituted by GCA, which encodes Ala.

The plasmids pBlueBacHis2B-Hel and pBlueBacHis2B-Hel-KA were used to derive two recombinant baculoviruses, designated vBac-Hel and vBac-Hel-KA, respectively. Cell culture, transfections, isolation of recombinant baculoviruses, plaque purifications, protein expression in High Five $^{\mathrm{TM}}$ insect cells (Invitrogen) and nickel-affinity chromatography purification were done as previously described (Seybert et al. 2000). The recombinant proteins purified from vBac-Hel- or vBac-Hel-KA-infected insect cells were designated HEL and HEL-KA, respectively.

\subsection{Nucleoside Triphosphatase Assay}

In the adenosine triphosphatase (ATPase) assay, HEL (3, 15 and 450 fmol, respectively) or HEL-KA (10 pmol) were incubated in a volume of 
$40 \mu \mathrm{l}$ containing $20 \mathrm{mM}$ HEPES-KOH $\mathrm{pH} 7.4,300 \mu \mathrm{M}$ ATP, $5 \mathrm{mM}$ magnesium acetate, $2 \mathrm{mM}$ dithiothreitol, $25 \mu \mathrm{g} / \mathrm{ml}$ bovine serum albumin and $250 \mathrm{nCi}$ of $\left[\gamma_{-}{ }^{32} \mathrm{P}\right] \mathrm{ATP}(3000 \mathrm{Ci} / \mathrm{mmol})$. In the guanosine triphosphatase (GTPase) assay, ATP and $\left[\gamma_{-}{ }^{32} \mathrm{P}\right]$ ATP were replaced by $300 \mu \mathrm{M}$ GTP and $250 \mathrm{nCi}\left[\gamma_{-}{ }^{32} \mathrm{P}\right]$ GTP $(3000 \mathrm{Ci} / \mathrm{mmol})$, respectively. When included, poly(U) was at a concentration of $150 \mu \mathrm{g} / \mathrm{ml}$. The reactions were incubated at $30^{\circ} \mathrm{C}$ for $30 \mathrm{~min}$ and stopped by adding EDTA to a final concentration of $100 \mathrm{mM}$. The samples were analyzed by polyethyleneimine-cellulose thin layer chromatography with $0.15 \mathrm{M}$ formic acid- $0.15 \mathrm{M} \mathrm{LiCl}(\mathrm{pH} 3.0)$ as the liquid phase. The reaction products were analyzed by phosphorimaging of the dried chromatographic plates (ImageQuant software; Molecular Dynamics, Sunnyvale, CA).

\subsection{Preparation of the Partial-Duplex DNA Substrate}

The synthetic oligonucleotide 5'-GGTGCAGCCGCAGCGGTGCTCG$\mathrm{d}(\mathrm{pT})_{30}{ }^{-3}$ ' was labelled with $\left[\gamma^{32} \mathrm{P}\right]$ ATP $(3000 \mathrm{Ci} / \mathrm{mmol})$ using T4 polynucleotide kinase and purified by phenol/chloroform extraction and gel filtration chromatography using Micro Bio-Spin 6 columns (Bio-Rad Laboratories, Munich, Germany). The DNA duplex was produced by annealing the labelled oligonucleotide to the oligonucleotide $5^{\prime}-\mathrm{d}(\mathrm{pT})_{30^{-}}$ CGAGCACCGCTGCGGCTGCACC-3' in buffer E (25 mM HEPES-KOH $\mathrm{pH} 7.4,500 \mathrm{mM} \mathrm{NaCl}, 1 \mathrm{mM}$ EDTA, $0.1 \%$ (w/v) SDS). The annealing reaction, which contained a tenfold excess of unlabelled DNA over $\left[\gamma-{ }^{32} \mathrm{P}\right]$ ATP-labelled DNA, was denatured for $5 \mathrm{~min}$ at $95^{\circ} \mathrm{C}$ and slowly cooled to room temperature. The resultant substrate was a twin-tailed ("forked") DNA duplex; i.e., it contained both 5' and 3' single-stranded regions on one end of the partial-duplex DNA.

\subsection{Duplex-Unwinding Assay}

HEL ( $30 \mathrm{fmol})$ or HEL-KA ( $210 \mathrm{fmol})$ were incubated in a volume of 40 $\mu 1$ with $15 \mathrm{fmol}$ of the partial-duplex DNA substrate for $30 \mathrm{~min}$ at $30^{\circ} \mathrm{C}$ in a buffer containing $20 \mathrm{mM}$ HEPES-KOH pH 7.4, $37.5 \mathrm{mM} \mathrm{NaCl}, 5 \mathrm{mM}$ ATP or GTP, respectively, $10 \%$ glycerol, $5 \mathrm{mM}$ magnesium acetate, $2 \mathrm{mM}$ dithiothreitol and $0.1 \mathrm{mg} / \mathrm{ml}$ bovine serum albumin. The reactions were stopped by the addition of $10 \mu \mathrm{l}$ of $5 \%(\mathrm{v} / \mathrm{v})$ SDS, $15 \%(\mathrm{w} / \mathrm{v})$ Ficoll and 100 mM EDTA. The reaction products were separated on $12 \%$ polyacrylamide$1 \times$ TBE gels (acrylamide/bis-acrylamide ratio of 19 to 1 ) at $4 \mathrm{~W}$ until the bromphenol blue dye approached the bottom of the gel. The gels were exposed to X-ray film at $-70^{\circ} \mathrm{C}$. 


\section{RESULTS AND DISCUSSION}

A recombinant form of the $\mathrm{HCoV}$ helicase, $\mathrm{HEL}$, has recently been shown to have ATPase activity in vitro (Seybert et al. 2000). To examine if HEL is also able to hydrolyze GTP, we have incubated $\left[\gamma_{-}{ }^{32} \mathrm{P}\right]$ GTP with HEL and the ATPase-deficient control protein HEL-KA. As Figure 1 (lane 2) shows, HEL effectively hydrolyzes GTP. We also found that the substrate conversion by HEL can be significantly stimulated by poly(U). Thus, in the presence of $150 \mu \mathrm{g} / \mathrm{ml}$ poly(U), $15 \mathrm{fmol}$ of HEL gave a similar rate of hydrolysis as $450 \mathrm{fmol} \mathrm{HEL}$ without the polynucleotide cofactor. Even very low amounts of enzyme gave significant GTPase activity if poly(U) was included (lane 6). The rate of GTP hydrolysis was found to be similar to that of ATP hydrolysis (Fig.1, cf. lanes 3, 5 and 4,6). As expected, no significant substrate hydrolysis was observed in the control reactions using buffer or HEL-KA (Figure 1, lanes 7 to 10). We conclude from these data that the $\mathrm{HCoV}$ helicase is able to effectively hydrolyze GTP and, in agreement with the structural model for the nucleic acid-induced activation of the Bacillus stearothermophilus PcrA helicase-associated ATPase activity (Soultanas et al. 1999), we propose that the binding to single-stranded RNA induces a

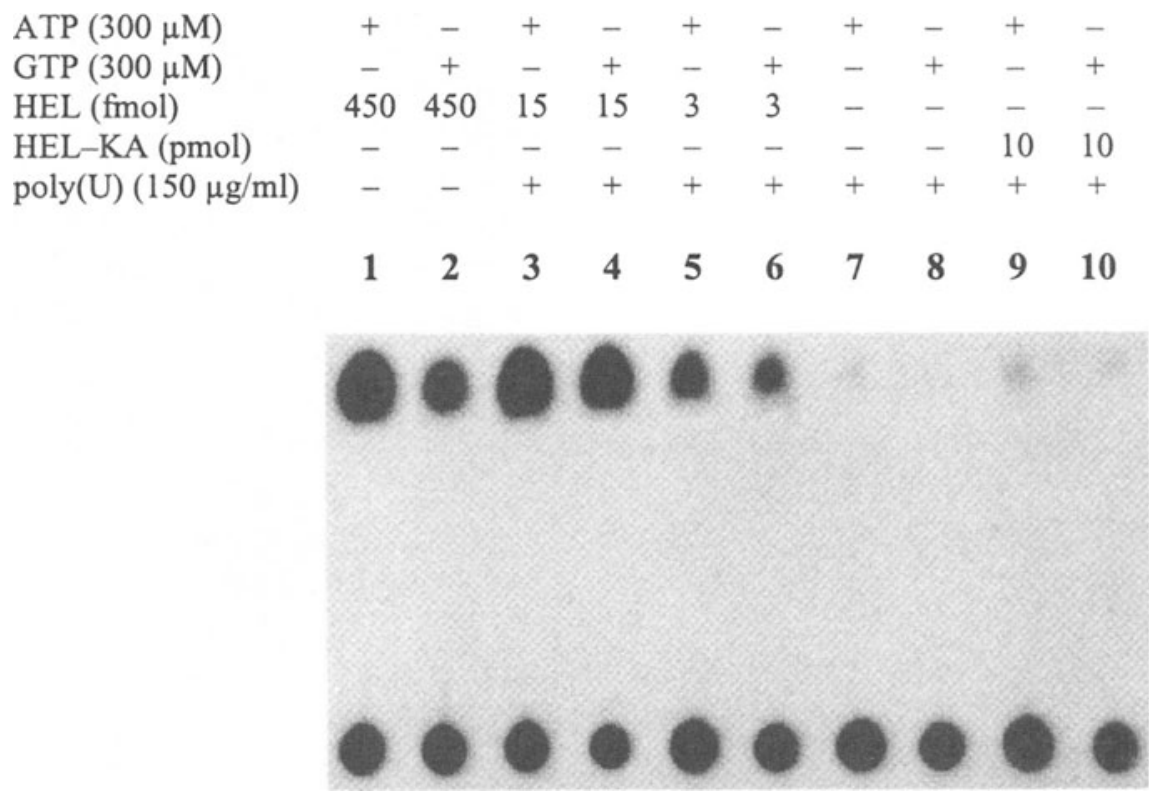

Figure 1. ATPase and GTPase activities of HEL. Reactions containing either $300 \mu \mathrm{M}$ ATP (lanes 1, 3, 5, 7, and 9) or $300 \mu \mathrm{M}$ GTP (lanes 2, 4, 6, 8, and 10) were incubated with (i) different amounts of HEL (lanes 1 to 6), (ii) buffer alone (lanes 7 and 8), or (iii) ATPasedeficient control protein HEL-KA (lanes 9 and 10). The reaction products were analyzed by thin-layer chromatography and phosphorimaging (see Materials and Methods for details). The composition of the individual reactions is indicated above. 
conformational change in the NTPase active site of HEL, which stabilizes the bound NTP molecule in a conformation that is required for rapid substrate hydrolysis.

It is generally accepted that the strand separation of nucleic acid duplexes by helicases is an energy-dependent process. Thus, NTP is a necessary cofactor for duplex-unwinding activity. In agreement with this model, we recently found that HEL requires ATP for duplex-unwinding activity. Also, the substitution of a lysine residue (Lys-5284 to Ala), which is part of the Walker A motif (Walker et al. 1982) and is predicted to be involved in binding and/or hydrolysis of NTP, resulted in an ATPase-deficient and, hence, helicase-deficient protein (HEL-KA).

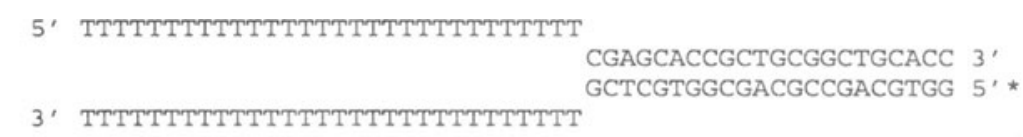

partially double-stranded (ds) DNA substrate

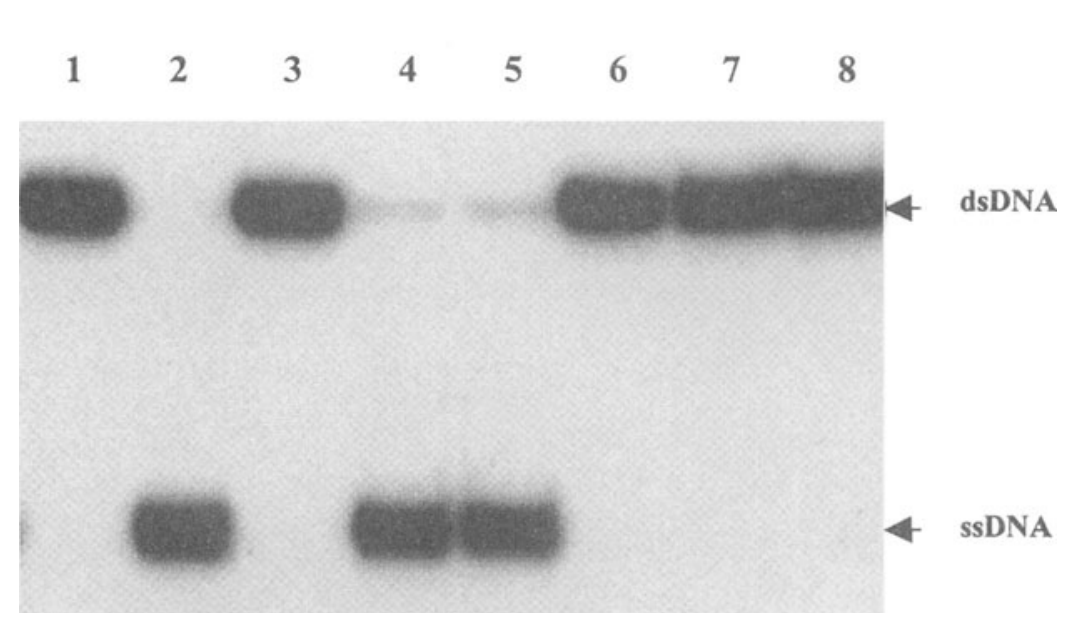

Figure 2. NTP-dependent DNA duplex-unwinding activity of HEL. Reaction conditions were as described in Materials and Methods with approximately 15 fmol of DNA substrate per reaction. The structure of the partial-duplex DNA substrate is shown schematically with the radiolabelled strand marked by an asterisk. The reaction products were separated on a nondenaturing $12 \%$ polyacrylamide gel and visualized by autoradiography. The positions of the partially double-stranded substrate (dsDNA) and the displaced, monomeric product (ssDNA) are indicated. Lanes: 1 , reaction without protein; 2 , heat-denatured DNA substrate; 3 , reaction containing $30 \mathrm{fmol} \mathrm{HEL}$ in the absence of NTP; 4, reaction containing $30 \mathrm{fmol}$ HEL in the presence of $5 \mathrm{mM} \mathrm{ATP} ; 5$, reaction containing $30 \mathrm{fmol} \mathrm{HEL}$ in the presence of $5 \mathrm{mM}$ GTP; 6 , reaction containing $210 \mathrm{fmol} \mathrm{HEL}-\mathrm{KA}$ in the absence of NTP; 7, reaction containing 210 fmol HEL-KA in the presence of $5 \mathrm{mM}$ ATP; 8, reaction containing 210 fmol HEL-KA in the presence of $5 \mathrm{mM}$ GTP. 


\section{ACKNOWLEDGMENTS}

This work was supported by grants from the Deutsche Forschungsgemeinschaft (SI 357/4-1) and the Fonds der chemischen Industrie (FCI).

\section{REFERENCES}

Gorbalenya, A.E., and Koonin, E.V., 1989, Viral proteins containing the purine NTP-binding sequence pattern. Nucleic Acids Res. 17: 8413-8440.

Gorbalenya, A.E., and Koonin, E.V., 1993a, Comparative analysis of the amino acid sequences of the key enzymes of the replication and expression of positive-strand RNA viruses. Validity of the approach and functional and evolutionary implications. Sov. Sci. Rev. D. Physicochem. Biol. 11: 1-84.

Gorbalenya, A.E., and Koonin, E.V., 1993b, Helicases: amino acid sequence comparisons and structure-function relationships. Curr. Opin. Struct. Biol. 3: 419-429.

Gorbalenya, A.E., Koonin, E.V., Donchenko, A.P., and Blinov, V.M., 1988, A novel superfamily of nucleoside triphosphate-binding motif containing proteins which are probably involved in duplex unwinding in DNA and RNA replication and recombination. FEBS Lett. 235: 16-24.

Gorbalenya, A.E., Koonin, E.V., Donchenko, A.P., and Blinov, V.M., 1989, Two related superfamilies of putative helicases involved in replication, recombination, repair and expression of DNA and RNA genomes. Nucleic Acids Res. 17: 4713-30.

Kadaré, G., and Haenni, A.L., 1997, Virus-encoded RNA helicases. J. Virol. 71: 2583-2590.

Koonin, E.V., and Dolja, V.V., 1993, Evolution and taxonomy of positive-strand RNA viruses: implications of comparative analysis of amino acid sequences. Crit. Rev. Biochem. Mol. Biol. 28: 375-430.

Lohman, T.M., and Bjornson, K.P., 1996, Mechanisms of helicase-catalyzed DNA unwinding. Annu. Rev. Biochem. 65: 169-214.

Schmid, S.R., and Linder, P., 1992, D-E-A-D protein family of putative RNA helicases. Mol. Microbiol. 6: 283-291.

Seybert, A., Hegyi, A., Siddell, S.G., and Ziebuhr, J., 2000, The human coronavirus 229E superfamily 1 helicase has RNA and DNA duplex-unwinding activities with 5'-to-3' polarity. RNA 6: in press.

Soultanas, P., Dillingham, M.S., Velankar, S.S., and Wigley, D.B., 1999, DNA binding mediates conformational changes and metal ion coordination in the active site of PcrA helicase. J. Mol. Biol. 290: 137-148.

Walker, J.E., Saraste, M., Runswick, M.J., and Gay, N.J., 1982, Distantly related sequences in the alpha- and beta-subunits of ATP synthase, myosin, kinases and other ATP-requiring enzymes and a common nucleotide binding fold. EMBO J. 1: 945-951.

Ziebuhr, J., Snijder, E.J., and Gorbalenya, A.E., 2000, Virus-encoded proteinases and proteolytic processing in the Nidovirales. J. Gen. Virol. 81: 853-879. 